\title{
Akt1/PKB upregulation leads to vascular smooth muscle cell hypertrophy and polyploidization
}

\author{
Mary L. Hixon, ${ }^{1,2}$ Carlos Muro-Cacho, ${ }^{3}$ Mark W. Wagner, ${ }^{4}$ \\ Carlos Obejero-Paz, ${ }^{4}$ Elise Millie, ${ }^{2}$ Yasushi Fujio, ${ }^{3}$ Yasuko Kureishi, ${ }^{3}$ \\ Terry Hassold, ${ }^{2}$ Kenneth Walsh, ${ }^{1}$ and Antonio Gualberto ${ }^{1,4,5}$ \\ ${ }^{1}$ Division of Cardiovascular Research, St. Elizabeth's Medical Center, Boston, Massachusetts, USA \\ ${ }^{2}$ Department of Genetics, Case Western Reserve University School of Medicine, Cleveland, Ohio, USA \\ ${ }^{3}$ Department of Pathology, H. Lee Moffitt Cancer Center and Research Institute, University of South Florida, \\ Tampa, Florida, USA \\ ${ }^{4}$ Department of Physiology and Biophysics, Case Western Reserve University School of Medicine, Cleveland, Ohio, USA \\ ${ }^{5}$ Department of Cardiovascular and Metabolic Diseases, Pfizer Global Research and Development, Groton Laboratories, \\ Groton, Connecticut, USA
}

Address correspondence to: Antonio Gualberto, Cardiovascular and Metabolic Diseases,

Pfizer Global Research and Development, Eastern Point Road, MS 8220-3128, Groton, Connecticut 06340, USA.

Phone: (860) 715-4617; Fax: (860) 686-0001; E-mail: antonio_gualberto@groton.pfizer.com.

Received for publication August 25, 1999, and accepted in revised form August 28, 2000.

Vascular smooth muscle cells (VSMCs) at capacitance arteries of hypertensive individuals and animals
undergo marked age- and blood pressure-dependent polyploidization and hypertrophy. We show here
that VSMCs at capacitance arteries of rat models of hypertension display high levels of Akt1/PKB pro-
tein and activity. Gene transfer of Akt 1 to VSMCs isolated from a normotensive rat strain was suffi-
cient to abrogate the activity of the mitotic spindle cell-cycle checkpoint, promoting polyploidization
and hypertrophy. Furthermore, the hypertrophic agent angiotensin II induced VSMC polyploidization
in an Akt1-dependent manner. These results demonstrate that Akt1 regulates ploidy levels in VSMCs
and contributes to vascular smooth muscle polyploidization and hypertrophy during hypertension.

J. Clin. Invest. 106:1011-1020 (2000).

\section{Introduction}

Aging is accompanied at the vascular system by changes in the morphology and hemodynamic properties of arterial vessels. These changes are specific for precise areas of the vascular tree. At capacitance arteries, the increase in mass and rigidity of the arterial wall contributes to systolic hypertension and constitutes an independent risk for left ventricular hypertrophy (1-3). Vascular smooth muscle cell (VSMC) hypertrophy with minimal hyperplasia accounts for the increase in smooth muscle mass in large arteries during hypertension $(4,5)$. VSMC hypertrophy is strongly associated with polyploidization (6-10). Polyploid VSMCs have up to fivefold the mass of diploid VSMCs (6) and, on a per cell basis, express higher levels of PDGF A, fibronectin, and collagen III than their diploid counterparts (11). Several stimuli, including catecholamines (12) and angiotensin II (13-17), have been shown to promote VSMC polyploidization. However, the molecular mechanisms that underlie the onset of VSMC polyploidization have not yet been characterized.

Mammalian cells are protected from polyploidization by the activity of the mitotic spindle cell-cycle checkpoint. This pathway prevents the onset of anaphase and the exit from mitosis until metaphase has been properly completed (18-20). The precise mechanism by which the mitotic checkpoint controls the progression and exit from mitosis (M phase) is not entirely under- stood, but it appears to involve a delay in the activation of the anaphase-promoting complex (APC). At the mitotic exit, the APC, also known as cyclosome, promotes the degradation of cyclin B by the mitotic proteosome, with the resulting inactivation of the $M$ phase-promoting complex (MPF; a complex of cyclin B, Cdc2, and associated proteins) (21).

Here, we have investigated the role of Akt1, also known as PKB, in VSMC polyploidization. Akt1 is a serine/threonine protein kinase that contains a region homologous to a pleckstrin domain found in multiple signaling molecules $(22,23)$. Akt 1 is stimulated by a number of receptor tyrosine kinases, including receptors for IGF, NGF, PDGF, VEGF, angiotensin, and insulin, by the action of phosphatidylinositol 3kinase (PI 3-kinase) (22-26). Akt1 has diverse regulatory functions. It promotes glucose transport through translocation of GLUT1 and GLUT4 to the plasma membrane $(27,28)$ and controls glycogen synthesis by insulin-dependent phosphorylation and inactivation of GSK-3 (29). Akt1 has also been shown to inhibit apoptosis in multiple cell types $(25,30-35)$. The antiapoptotic activities of Akt 1 are thought to be mediated by phosphorylation of the proapoptotic protein BAD (36-38), procaspase 9 (39), and a forkhead transcription factor (40-43). Akt1 also phosphorylates endothelial cell nitric oxide synthase, which regulates vasomotor tone (21). 
We report here a new function of Akt 1 , the regulation of ploidy in vascular smooth muscle. We show that Akt1 protein levels and activity are elevated in VSMCs at capacitance arteries of hypertensive rats. Since Akt1 is well known to provide signals that promote cell growth (44-47), we hypothesized that an increase in Akt1 activity may be involved in the onset of VSMC polyploidization. To test this hypothesis, we generated populations of primary VSMCs overexpressing a wildtype or a catalytic inactive Akt 1 mutant and investigated the ability of these cells to control the progression of mitosis. VSMCs with enhanced Akt1 expression underwent unscheduled cyclin B degradation and reentered the cell cycle at a tetraploid DNA content, generating polyploid and hypertrophic cells. Furthermore, angiotensin II, an activator of Akt1 in VSMCs (26, 48-50), induced Akt1-dependent VSMC polyploidization. These results demonstrate that Akt 1 is a positive regulator of the progression of mitosis in VSMCs and implicate this protein in the mechanism of hypertension-related VSMC polyploidization and hypertrophy.

\section{Methods}

Animals and histology. Spontaneously hypertensive rats (SHR) and Wistar Kyoto (WKY) rats were obtained from Charles River Laboratories (Wilmington, Massachusetts, USA). Zucker rats were obtained from Harland Sprague Dawley (Indianapolis, Indiana, USA). Two-kidney oneclip Goldblatt WKY rats were purchased from Taconic Farms (Germantown, New York, USA). Rats were sacrificed in accordance with American Veterinary Medicine Association recommendations and tissues rapidly processed for culture, histology, or extract preparation. Blood pressures were determined using tail cuffs and a programmed electrosphygmomanometer following the recommendations of the manufacturer (Narco Bio-Systems, Austin, Texas, USA). For histology, arteries were fixed in $10 \%$ formalin for a minimum of 12 hours and embedded in paraffin. Consecutive $5-\mu \mathrm{m}$ tissue sections were deparaffinized in xylene, rehydrated in a series of increasingly diluted solutions of ethanol, and processed for Feulgen and periodic acid-Schiff-hematoxylin (PAShematoxylin) staining (51). Quantitative DNA analysis was carried out using a CAS200 microdensitometer (Becton Dickinson, San Jose, California, USA). Three hundred VSMC nuclei were quantified per sample. At our measurement conditions and using human bladder cells as standard, we regarded VSMCs with a DNA content of 6-9 pg DNA per nucleus as diploid cells, cells with 12-18 pg DNA per nucleus as tetraploid, and cells with a DNA content over $18 \mathrm{pg}$ as octaploid $(8,52)$. Immunohistochemistry was carried out using Vectastain-ABC kits (Vector Laboratories, Burlingame, Massachusetts, USA) and Akt1 Ab (Santa Cruz Biotechnologies, Santa Cruz, California, USA) at a dilution of 1:50.

Isolation, infection, and culture of VSMCs. VSMCs were isolated following the method described in detail by Owens and coworkers (53). Briefly, vessels were excised, placed in PBS, and adhering fat and connective tissue removed by dissection. Vessels were then preincubated at $37^{\circ} \mathrm{C}$ for 15 minutes in PBS with $1 \mathrm{mg} / \mathrm{ml}$ collagenase II (Worthington, Freehold, New Jersey, USA), $0.5 \mathrm{mg} / \mathrm{ml}$ elastase $\mathrm{I}$ (Worthington), $100 \mathrm{U} / \mathrm{ml}$ penicillin, and streptomycin $\left(100 \mu \mathrm{g} / \mathrm{ml}\right.$; protease solution) in $5 \% \mathrm{CO}_{2}$. Their adventitia was then carefully removed under the dissecting microscope. Vessels were subsequently opened longitudinally and the luminal endothelia scraped with forceps. The smooth muscle layer was then minced into $2-\mathrm{mm}$ sections and digested in fresh protease solution for 2 hours, as above. The cellular suspension was filtered through a mess and cells were pelleted, washed three times in PBS, seeded at a density of 3,500 cells $/ \mathrm{cm}^{2}$, and grown in DMEM media supplemented with 10\% FBS and penicillin/streptomycin (Life Technologies Inc., Gaithersburg, Maryland, USA). The VSMC phenotype was verified by immunostaining using specific Ab's against smooth muscle $\alpha$-actin and smooth muscle myosin heavy chain, as described previously $(53,54)$. Population-doubling times were determined by plating VSMCs at low density and determining the cell number over several days. For that purpose, cell counts from several dishes were averaged daily using a Coulter model ZF cell counter beginning 1 day after plating.

Replication-defective adenovirus constructs expressing mouse Akt1 proteins under the control of the cytomegalovirus (CMV) promoter were as described previously $(25,35)$. The AA Akt 1 construct contains the mutations T308A and S473A and cannot be activated by phosphorylation (55). Ad- $\beta$ Gal expresses the bacterial $\beta$ galactosidase gene from the CMV promoter. Adenoviral constructs were amplified in 293 cells and purified by ultracentrifugation through a $\mathrm{CsCl}$ gradient. VSMCs were infected for 24 hours at a moi of 1-100 $(25,35)$.

Akt 1 kinase assays. Akt 1 activity was measured using the method described by Tsichlis and coworkers (24). Briefly, vascular smooth muscle was disrupted using a Branson sonifier at setting 4 in lysis buffer (1\% NP- $40,10 \%$ glycerol, $137 \mathrm{mM} \mathrm{NaCl}, 20 \mathrm{mM}$ Tris- $\mathrm{HCl}$ at $\mathrm{pH}$ 7.4) containing $5 \mu \mathrm{g} / \mathrm{ml}$ of the protease inhibitors aprotinin and leupeptin, $1 \mathrm{mM}$ PMSF, $1 \mathrm{mM} \mathrm{NaF}, 1 \mathrm{mM}$ sodium pyrophosphate, and $1 \mathrm{mM}$ sodium orthovanadate. Lysates (100 $\mu \mathrm{g}$ protein) were precleared by centrifugation and preabsorbed with protein $\mathrm{A} / \mathrm{G}$ agarose slurry. Immunoprecipitation of Akt 1 was carried out for 4 hours using a specific $\mathrm{Ab}$ (Santa Cruz Biotechnologies). Immunoprecipitates were washed three times with lysis buffer, once with water, and once with kinase buffer. Kinase assays were performed in Akt kinase buffer (20 mM HEPES- $\mathrm{NaOH}, 10 \mathrm{mM}$ magnesium chloride, and $10 \mathrm{mM}$ manganese chloride). Kinase activity was assayed for 20 minutes at $30^{\circ} \mathrm{C}$ in a $30-\mu l$ volume of kinase buffer with $5 \mu \mathrm{M} \mathrm{ATP}, 100 \mu \mathrm{g} / \mathrm{ml}$ histone $2 \mathrm{~B}$, and $20 \mu \mathrm{Ci}$ $\left[\gamma^{32}\right]$ ATP per sample. Reactions were stopped by an equal volume of $2 \times$ SDS buffer-PAGE sample buffer. The products of the in vitro kinase assay were analyzed by $15 \%$ SDS/PAGE and exposure to PhosphorImager screens. VSMC fractionation in Percoll density gradients. Cell fractionation was performed as described previously (56) 
using Percoll gradients (Pharmacia Biotech AB, Uppsala, Sweden) diluted in PBS, pH 7.4, containing 5 $\mathrm{mg} / \mathrm{ml}$ BSA (Sigma Chemical Co., St. Louis, Missouri, USA). Thirty to seventy percent gradients were prepared fresh in $15-\mathrm{ml}$ centrifuge tubes by layering from below, upwards $1 \mathrm{ml}, 70 \% ; 3 \mathrm{ml}, 52 \%$; $4 \mathrm{ml}, 42 \%$; and 5 $\mathrm{ml}, 30 \%$ Percoll. VSMCs $\left(10^{7}\right.$ Akt1 wild-type transduced) were resuspended in DMEM media, loaded onto the gradients, and centrifuged at $20,000 \mathrm{~g}$ for 1 hour. Density bands were determined using Pharmacia Biotech $\mathrm{AB}$ marker beads. Low ploidy factions were obtained at the $1.08 \mathrm{~g} / \mathrm{l}$ density band of exponentially growing VSMCs. High ploidy fractions were obtained at the $1.04 \mathrm{~g} / \mathrm{l}$ density band of 1 -week colcemid-treated $(100 \mathrm{ng} / \mathrm{ml})$ VSMCs. Cell fractions were isolated by pipetting, washed twice in DMEM media, and processed for flow cytometry or Western analysis.

Analysis of cell-cycle checkpoint status. Matched sets of VSMC populations were incubated for a 1-2 populationdoubling time periods in media with the mitotic spindle inhibitor colcemid (100 ng/ml). Cell-cycle distribution of DNA content was determined by flow cytometry as described previously $(57,58)$. When both total DNA content and newly synthesized DNA were determined, cells were labeled with $10 \mu \mathrm{M}$ bromodeoxyuridine (BrdU) for 4 hours, trypsinized, counted, and fixed using 70\% ethanol. Fixed cells were centrifuged and treated with $0.08 \%$ pepsin for the preparation of nuclei. The nuclear pellet was resuspended in $100 \mu \mathrm{l}$ of a 1:5 dilution of antiBrdU FITC-conjugated Ab (Becton Dickinson), incubated for 30 minutes, washed, stained with $50 \mu \mathrm{g} / \mathrm{ml}$ propidium iodide (Aldrich Chemical Co., Milwaukee, Wisconsin, USA), and analyzed by flow cytometry for cell-cycle distribution of DNA content. Flow cytometry was carried out using a Coulter Elite ESP flow cytometer and analyzed using CellQuest software (Becton Dickinson), and cells $\left(10^{4}-4 \times 10^{4}\right.$ per sample) were analyzed.

For karyotyping (57), exponentially growing cells were exposed to $100 \mathrm{ng} / \mathrm{ml}$ colcemid for two population-doubling times, and then collected and incubated at room temperature for 30 minutes in hypotonic $\mathrm{KCl}$ plus sodium citrate, followed by fixation in methanol/acetic acid and staining with Giemsa; 16-39 spreads per VSMC population were examined.

Western blots. For Western blot analysis, cells were harvested and lysed in $1 \mathrm{ml}$ lysis buffer-PBS containing 1\% Triton X-100, 0.1\% SDS, $1 \mathrm{mM}$ DTT, $1 \mathrm{mM}$ PMSF, and 1 $\mu \mathrm{g} / \mathrm{ml}$ of the protease inhibitors aprotinin, leupeptin, and pepstatin $\mathrm{A}$, followed by centrifugation at $1500 \mathrm{~g}$ for 5 minutes. Equal amounts of proteins were assayed at each condition as determined by Bradford protein assay (Bio-Rad, Hercules, California, USA). Electrophoresis was carried out at $20 \mathrm{~mA}$ constant current in 15\% PAGE (BioRad). Proteins were transferred to Immobilon-P membranes (Millipore Corp., Bedford, Massachusetts, USA) and probed, following the recommendation of the manufacturers. Anti-Akt1 (Santa Cruz Biotechnologies), anticyclin B (Santa Cruz Biotechnologies), and anti- $\beta$ actin (Sigma Chemical Co.) Ab's were employed at dilution of $1: 500,1: 500$, and 1:10,000, respectively, in PBS-5\% dry milk. Membranes were hybridized overnight at $4^{\circ} \mathrm{C}$. For detection, membranes were incubated for 1 hour in $1: 10,000$ or $1: 5,000$ dilutions of horseradish peroxidase-linked (HRP-linked) IgG (Santa Cruz). HRP-luminescence reactions were carried out using the enhanced chemiluminescence (ECL) kit (Amersham Corp., Burlington, Massachusetts, USA). Membranes were exposed to Hyperfilm (Eastman Kodak Co. Scientific Imaging Systems, New Haven, Connecticut, USA) and protein bands detected by autoradiography. Low-exposure autoradiographs were scanned with a densitometer (LKB-Wallac, Stockholm, Sweden) to determine peak areas.

Determination of VSMC bypertrophy. $\left[{ }^{3} \mathrm{H}\right]$ leucine incorporation was carried out as described (26). Briefly, VSMCs were made quiescent by incubation in $1 \%$ DMEM for 72 hours. Twenty-four hours before harvesting, $\left[{ }^{3} \mathrm{H}\right]$ leucine $(1 \mu \mathrm{Ci} / \mathrm{ml})$ (NEN Life Science Products, Boston, Massachusetts, USA) was added to the media. VSMCs were washed twice in PBS, proteins precipitated in $5 \%$ trichloroacetic acid, and $\left[{ }^{3} \mathrm{H}\right]$ leucine incorporation determined using a LS 3801 scintillation counter (Beckman Instruments Inc., Fullerton, California, USA). Forward-scatter cell fluorescence and side-scatter cell fluorescence were determined using a Coulter Elite ESP flow cytometer and analyzed using CellQuest software (Becton Dickinson). VSMCs $\left(4 \times 10^{4}\right.$ per sample) were analyzed.

\section{Results}

Akt1 protein and activity are upregulated in VSMCs of three animal models of hypertension. Akt1 protein expression was analyzed in VSMCs of hypertensive rats by Western blot analysis. Initial experiments compared SHR to normotensive WKY rats. SHR rates develop hypertension spontaneously and without exception by $7-15$ weeks of age (59). Vascular smooth muscle extracts were prepared

Table 1

Frequency of polyploid VSMCs in sections of proximal aortas isolated from control and hypertensive rats

\begin{tabular}{lcccccccc}
\hline Animal & Zucker lean & Zuckerfa/fa & WKY & SHR & Zucker lean & Zucker fa/fa & WKY & $\begin{array}{c}\text { SHR } \\
\text { 3 mo }\end{array}$ \\
Age & 3 weeks & 3 weeks & 4 weeks & 4 weeks & 3 months & 3 months & 4 months & 4 months \\
Weight & - & - & - & - & $281 \pm 8$ & $423 \pm 8$ & - & - \\
MBP & $86 \pm 4$ & $88 \pm 6$ & $100 \pm 6$ & $106 \pm 9$ & $104 \pm 7$ & $131 \pm 8$ & $116 \pm 9$ & $168 \pm 12$ \\
$>4 \mathrm{~N}$ & $<1 \%$ & $<1 \%$ & $<1 \%$ & $<1 \%$ & $5 \%$ & $14 \%$ & $7 \%$ & $22 \%$ \\
\hline
\end{tabular}

Mean blood pressure (MBP) and cell ploidy were determined as indicated in Methods. Three hundred VSMCs per group from three independent preparations were scored for ploidy determinations. MBP data represent five to nine animals. 


\section{Figure 1}

Akt 1 protein levels and activity are upregulated in vascular smooth muscle of hypertensive rats. (a-d) Western blot analysis of Akt 1 protein in aortic VSMCs freshly isolated from 3-week-old WKY and SHR rats (a), 4-month-old WKY and SHR rats (b), 4-month-old WKY and WKY-Goldblatt rats (c), and 4-month-old Zucker lean and fa/fa rats (d). As a control, blots were probed for $\beta$-actin expression. Each lane represents Akt $1 / \beta$-actin levels in protein extracts of VSMCs isolated from the upper two-thirds of the thoracic aorta of nine animals; n.s., nonspecific, band reactive with secondary Ab. Western blotting was carried out as indicated in Methods. Three hundred fifty micrograms of protein extract was employed in gel in c and $200 \mu \mathrm{g}$ in gels used in $\mathbf{a}, \mathbf{b}$, and $\mathbf{d}$. Goldblatt-WKY rats underwent left renal artery constriction for 6 weeks (mean blood pressure [MBP] $=123 \pm 4$, sham-operated; $\mathrm{MBP}=180 \pm 12$, Goldblatt). MBPs of WKY, SHR, and Zucker animals were within the range shown in Table 1 . Parts $\mathbf{a}$ and $\mathbf{b}$ are representative of three preparations and $\mathbf{c}$ is representative of two preparations. (d) Two independent preparations of Zucker lean and fa/fa rats. (e) Akt1 activity in 4-month-old control (WKY and Zucker lean) and hypertensive rats (SHR and Zucker fa/fa). Activity was measured as histone $\mathrm{H} 2 \mathrm{~B}$ phosphorylation, as indicated in Methods. Bars indicate Phosphorlmager scans of phosphorylated histone $\mathrm{H} 2 \mathrm{~B}$ bands in arbitrary units relative to Akt1 activity in extracts of Zucker lean animals. Data are representative of three independent experiments.

from the aortas of 3-week-old and 4-month-old WKY and SHR rats and processed for Western blot analysis. Markedly greater Akt 1 protein levels, approximately fivefold, were found in the SHR strain at both stages (Figure 1 , a and $b)$. In the older animals, an additional fastermigrating band was observed. This band was reactive with our secondary $\mathrm{Ab}$ and was designated "nonspecific" (Figure 1, n.s.). To test whether genetic divergence might account for the differences in Akt1 protein expression between WKY and SHR rats, two additional models of experimental hypertension were investigated. In one of these models, the renin-angiotensin system was activated in WKY rats by clipping the left renal artery (referred to as Goldblatt's operation), a procedure that has been shown to induce VSMC hypertrophy and polyploidization at capacitance arteries (17). Enhanced expression of Akt 1 protein was observed in smooth muscle extracts from the aortas of Goldblatt rats relative to their mock-operated controls (Figure 1c). We also inves-

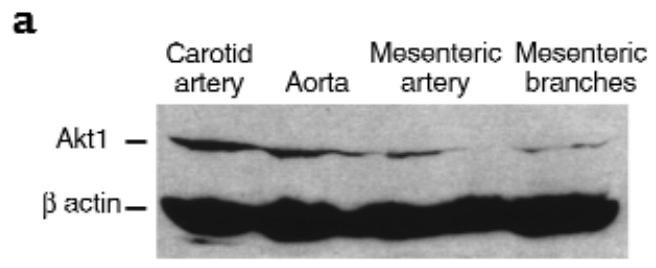

\section{Figure 2}

Akt1 upregulation is specifically localized to capacitance arteries. (a) Levels of Akt 1 protein in vascular smooth muscle of 3-week-old SHR rats. Western blot analysis was performed as indicated in Figure 1. Figure is representative of two experiments. (b) Akt 1 immunohistochemistry in longitudinal sections of arterial vessels dissected from 3 -week-old WKY and SHR rats. $\times 250$. Immunohistochemistry was performed as indicated in Methods. Microphotographs are representative of at least ten slides per four animals.

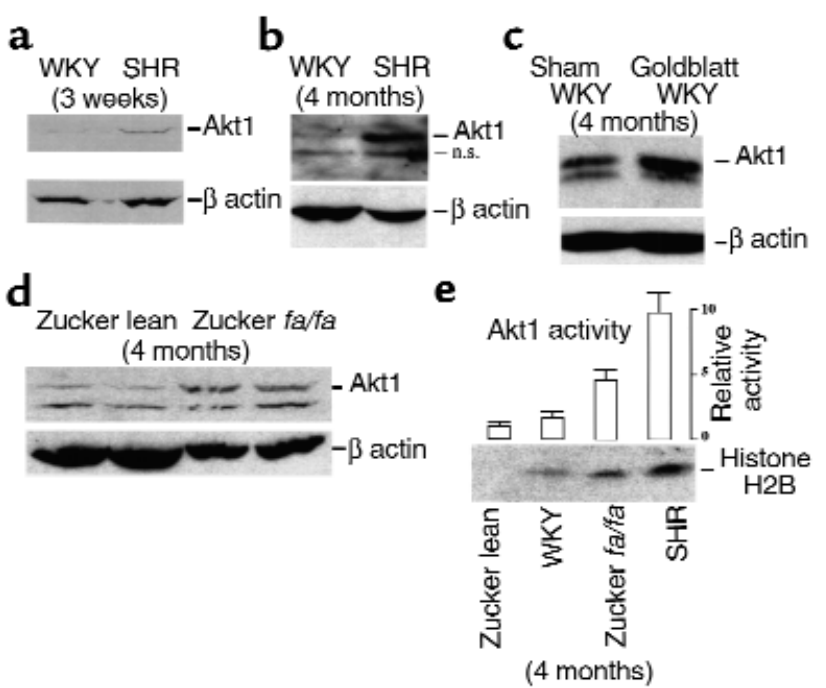

tigated the expression level of Akt 1 protein in Zucker lean and $f a / f a$ rats. The Zucker $f a / f a$ rat is a model of obesity and moderate hypertension (60). Three-week-old animals expressed barely detectable Akt1 protein levels, with no differences between Zucker lean and $f a / f a$ rats (not shown). However, threefold higher levels of Akt1 protein were found at 4 months in the hypertensive $f a / f a$ group (Figure 1d and Table 1). Furthermore, the increase in Akt 1 protein level was accompanied by enhanced Akt1 kinase activity. Akt 1 assays were performed using vascular smooth muscle extracts from 4-month-old WKY, SHR, and Zucker rats. The results of these experiments, shown in Figure 1e, demonstrated that changes in Akt1 kinase activity in vivo correlate with those of Akt 1 protein levels. Maximal Akt1 kinase activity was found in SHR rats, approximately fourfold higher than agematched WKY controls.

The development of hypertension in SHR and Goldblatt WKY rats is accompanied by VSMC polyploidiza-

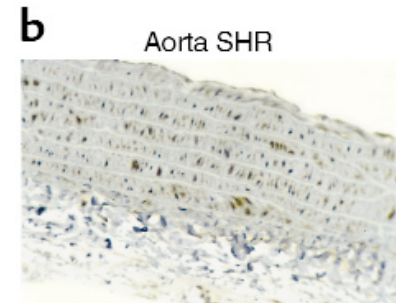

Mesenteric artery SHR

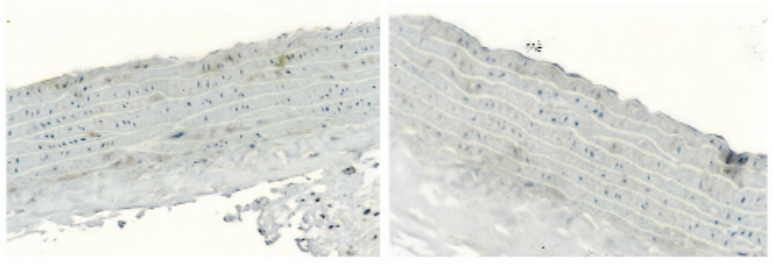




\section{Figure 3}

Akt1 overexpression in VSMCs by adenovirus gene transfer. (Top) Western blot analysis demonstrating overexpression of Akt 1 constructs in adenovirus-infected aortic VSMCs isolated from 3-week-old WKY rats. Adenovirus containing $\beta$ Gal, wild-type Akt1, and double-mutant T308A/S473A Akt1 (Akt1 AA) are described in Methods. Data are representative of two experiments. Other details as in Figure 1. (Bottom) Akt1 activity in control ( $\beta$ Gal) and Akt1-expressing VSMC. Experimental details as in Figure 1. Data are representative of two experiments.

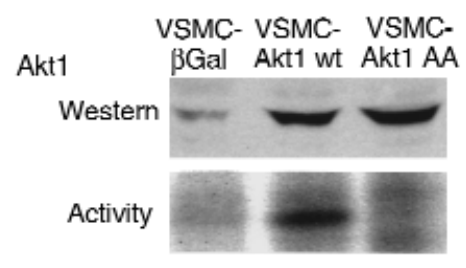

tion at capacitance arteries $(6,17)$, but this phenomenon has not been reported previously in Zucker $f a / f a$ rats. Therefore, ploidy levels were determined in aortas of Zucker $f a / f a$ rats using in situ DNA microdensitometry. WKY and Zucker lean rats were employed as negative controls and SHR rats as positive controls. Table 1 shows that hypertension in Zucker fa/fa rats is accompanied by VSMC polyploidization. Together, the results shown in Figure 1 and Table 1 demonstrate a correlation between hypertension, polyploidization, and elevated levels of Akt1 protein and activity in VSMCs.

Previous studies have shown that the phenomena of VSMC polyploidization and hypertrophy are limited to vessels of capacitance function, such as the aorta and carotid arteries $(52,61-63)$. Thus, we also investigated whether Akt1 protein was upregulated differentially depending upon localization within the vascular tree. Consistent with a role in hypertension-related hypertrophy and polyploidization, high levels of Akt1 protein expression were detected by Western analysis in the aorta and carotid arteries of SHR (Figure 2). In contrast, low levels of Akt1 protein were detected at small arteries, such as III and IV branches of the superior mesenteric artery. Moreover, immunohistochemical assays demonstrated that Akt1 upregulation was restricted to the medial smooth muscle layer of capacitance arteries (upper aorta), with background staining at the vascular adventitia (Figure 2).

Akt1 promotes VSMC endoreduplication. In view of these results and the reported pro-proliferative and antiapoptotic properties of Akt1 (64), we hypothesized that an increase in Akt1 activity in VSMCs of hypertensive animals could contribute to their polyploidization. To test this hypothesis, Akt 1 was overexpressed in VSMCs isolated from the aorta of 3-week-old normotensive WKY rats using an adenovirus vector that encodes wildtype murine Akt1 (Akt1 wt)(25, 35). VSMCs were also infected with adenoviruses that encode the catalytic inactive Akt1 mutant T308A/S473A (Akt1 AA), or the $\beta$-galactosidase gene $(\beta \mathrm{Gal})$. Overexpression of Akt1 was verified by Western blot analysis (Figure 3). As expected, we observed an increase in basal Akt1 activity in VSMC-overexpressing wild-type Akt1, but not in those overexpressing the catalytic inactive Akt1 AA mutant (Figure 3).

The adenovirus-infected VSMC populations were analyzed for their ability to control cell-cycle progression at the metaphase-to-anaphase transition, using the flow cytometry-based assay described previously (57). Incubation of wild-type Akt1-overexpressing VSMCs (VSMC-Akt1 wt cells) for two population-dou- bling times in the presence of a mitotic inhibitor resulted in dramatic progression to octaploid DNA content (4N, Figure $4 a$ ). In contrast, VSMCs expressing $\beta$-galactosidase or the catalytic inactive Akt1 AA mutant were able to arrest growth at $4 \mathrm{~N}$, with minor progression to $4 \mathrm{~N}$ (Figure 4a). Moreover, when primary VSMCs were infected with increasing moi's of wild-type Akt1 adenovirus, a direct correlation was observed between Akt1 transduction and VSMC polyploidization (Figure 4b). Furthermore, double staining of total DNA content (propidium iodide staining) versus newly synthesized DNA (BrdU incorporation) indicated that VSMC-Akt1 wt underwent cell-cycle reentry at $4 \mathrm{~N}$ DNA content (Figure 4c). These results demonstrated that Akt1 overexpression promotes endoreduplication in VSMCs.

Overexpression of Ak1 causes altered mitotic spindle cell-cycle checkpoint status in VSMCs. The fact that VSMCs overexpressing wild-type Akt 1 may undergo endoreduplication indicates a loss of mitotic spindle cell-cycle checkpoint activity in these cells. The mitotic spindle cell-cycle checkpoint regulates exit from mitosis by controlling the metabolism of M-phase regulators, such as cyclin B (65). When cells cannot segregate their chromosomes appropriately, the degradation of cyclin B and, consequently, the progression from mitosis to a new G1-phase, is delayed (58). To determine the status of the mitotic checkpoint in Akt1-transduced VSMCs, we investigated the ability of these cells to regulate cyclin B turnover in response to the inhibition of their chromosomal segregation (58). Cells were made quiescent and then stimulated to enter the cell cycle synchronously in the presence or absence of colcemid. In the absence of microtubule inhibitor, cyclin B protein levels oscillated similarly in all cell groups. Cyclin B protein reached maximal levels at 48 hours and decreased to barely detectable levels at 72 hours, indicating entry and exit from mitosis (Figure 5, a-c; no colcemid). In wild-type Akt1-transduced cells, cyclin B expression was observed as early as 24 hours, suggesting shortening of G1 or S cell-cycle phases (Figure 5c; no colcemid), in agreement with previous reports (66). Importantly, a differential ability to regulate cyclin B degradation in response to colcemid was observed (Figure 5, a-c; colcemid). In $\beta$-Gal and Akt1 mutant-transduced cells, cyclin B levels remained elevated for up to 120 hours. This delay in the onset of cyclin B degradation indicated the activity of the mitotic spindle cell-cycle checkpoint and was similar in length to what has been observed previously in normal human fibroblasts (58). However, when wild-type Akt1-overexpressing 

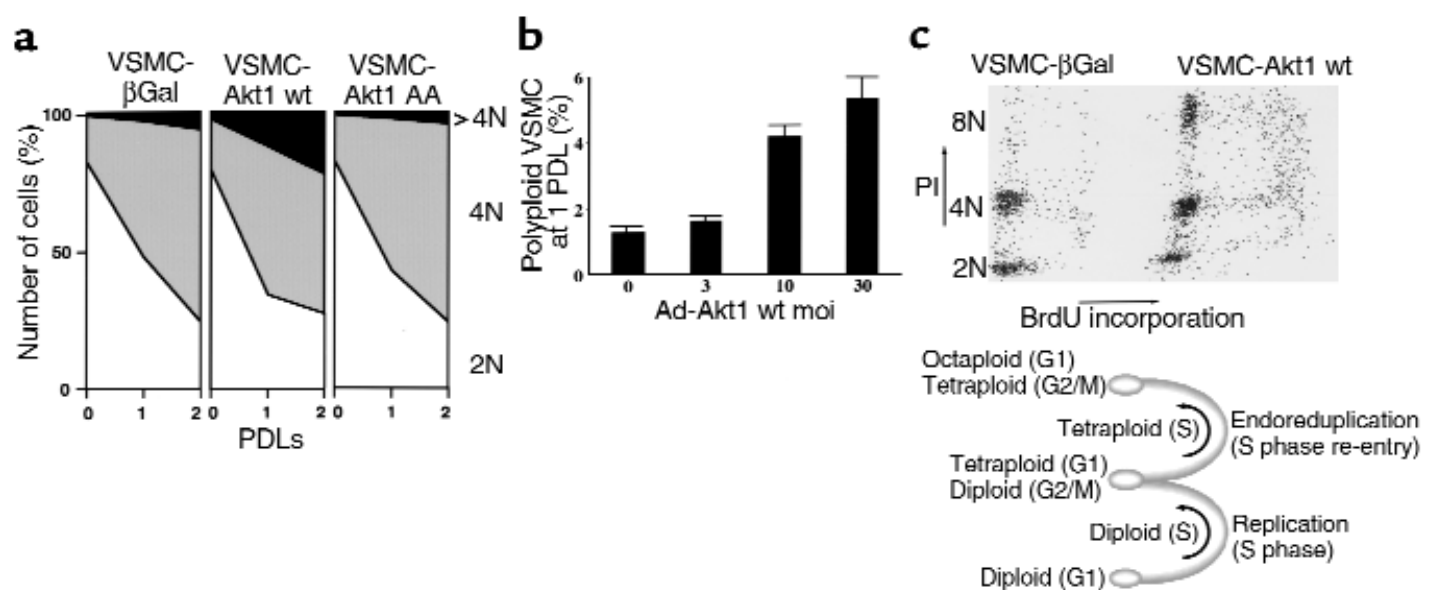

\section{Figure 4}

Akt1-transduced VSMCs fail to arrest growth at mitosis. (a) Cell-cycle analysis of DNA content in control and Akt1-overexpressing VSMCs. Cells were exponentially growing (0 population-doubling time [PDL]) or incubated with $100 \mathrm{ng} / \mathrm{ml}$ of colcemid for one or two PDLs (1, 2 PDL). Graphs show $10^{4}$ cells. PDLs were 63 ( $\beta$ Gal), 58 (Akt1 wt), and 62 (Akt1 AA) hours. VSMCs were fixed in 70\% ethanol, nuclei isolated, stained with propidium iodide, and processed for flow cytometry, as indicated in Methods. Graphs represent the distribution in $2 \mathrm{~N}, 4 \mathrm{~N}$, and greater than $4 \mathrm{~N}$ DNA content of $10^{4}$ VSMCs per time point. (b) Akt1 causes VSMC polyploidization. VSMCs (WKY aorta, 3 weeks old) were transduced with the indicated moi's of Akt $1 \mathrm{wt}$ adenovirus. Forty-eight hours after infection, cells were passed and incubated in new media with $100 \mathrm{ng} / \mathrm{ml}$ of colcemid for 72 hours. DNA content was determined by flow cytometry, as above. The figure indicates the percentage of VSMCs with greater than 4N DNA content. Data are representative of three experiments. (c) Flow cytometry analysis of total DNA content (propidium iodide staining) and newly synthesized DNA (BrdU incorporation) of VSMC-Akt1 wt cells incubated for two population-doubling times in the presence of $100 \mathrm{ng} / \mathrm{ml}$ of colcemid. Other experimental details as indicated in Methods. Data are representative of three experiments.

VSMCs were incubated in colcemid, cyclin B levels declined between 48 hours and 72 hours. Thus, VSMCs with high Akt1 levels failed to maintain cyclin $\mathrm{B}$ levels in response to mitotic spindle depolymerization, demonstrating that overexpression of Akt 1 alters the activity of the mitotic spindle cell-cycle checkpoint in VSMCs. Expression of a control protein, $\beta$ actin, in extracts from these cell groups was similar at all time points investigated (not shown).

Akt1 promotes VSMC polyploidization and hypertrophy. Although the results shown in Figures 4 and 5 demonstrate that Akt1 upregulation promotes endoreduplication in VSMCs, they do not provide formal proof of VSMC polyploidization. Thus, karyotypic analyses were performed to confirm whether or not overexpression of Akt 1 is sufficient to induce polyploidiza-

\section{Figure 5}

Unscheduled cyclin B degradation in Akt1 wt-transduced VSMCs. VSMCs infected with adenoviruses $\beta$ Gal (a), T308A/S473A Akt 1 mutant (b), AA Akt1 mutant, or wild-type Akt1 (c) were synchronized as above, then incubated at low density $\left(1-2 \times 10^{4}\right.$ cells $/ \mathrm{cm}^{2}$ ) in $10 \%$ FBS in the absence or presence of $100 \mathrm{ng} / \mathrm{ml} \mathrm{col}-$ cemid and harvested at the indicated intervals. Colcemid was added at 16 hours after cell passage. Western blotting of cyclin B was carried out as indicated in Methods. Data are representative of three independent experiments. tion in VSMCs. Control and wild-type Akt1-transduced VSMC populations had a low number of polyploid cells (1-3\%). However, when these cells were incubated in the presence of colcemid for two population-doubling time periods, a high polyploid fraction was observed in VSMCs transduced with wildtype Akt1, but not with Akt1 AA or $\beta$ Gal adenovirus (Figure 6b). Of note, chromosomal counts were multiples of the diploid number, supporting endoreduplication as the mechanism of polyploidization in VSMCs. Subsequent experiments, shown in Figure 6c, investigated the ploidy content of control and wildtype Akt1-transduced VSMCs after successive passage in culture. Higher ploidy fractions were found in VSMCs transduced with wild-type Akt1. Thus, cell populations overexpressing wild-type Akt1 may under-

a

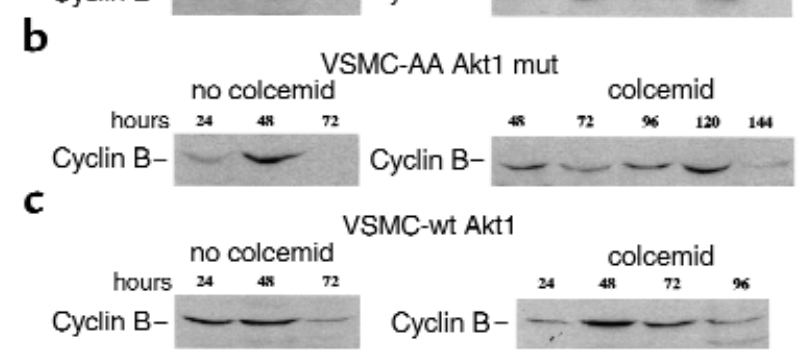


Figure 6

Akt1 promotes VSMC polyploidization. (a) Microphotographs of a diploid and a tetraploid VSMC with enhanced Akt1 expression. (b) Karyotypic analysis of control and Akt1-overexpressing VSMC populations incubated for two population-doubling times in the presence of $100 \mathrm{ng} / \mathrm{ml}$ of colcemid. Figure represents G-banding and chromosome counts of 36-39 metaphase spreads. (c) Karyotypic analysis of control ( $\beta \mathrm{Gal}$ ) and Akt1-overexpressing (Akt1 wt) VSMC populations five tissue culture passages after viral transduction (15-20 days). Parental VSMCs were analyzed at the time of infection. VSMCs received 100 moi per week of the respective adenovirus. Gbanding was performed after 4 hours' incubation in colcemid.

go spontaneous polyploidization in tissue culture, a phenomenon described previously in VSMCs isolated from hypertensive animals (67).

Since polyploid VSMCs are hypertrophic, we extended our observations to the analysis of the effects of Akt1 on VSMC size and protein synthesis. Forwardscatter cell (FSC) fluorescence flow cytometry demonstrated a $36 \%$ increase in cell size in wild-type Akt1-transduced VSMCs (Figure 7a). Furthermore, analysis of $\left[{ }^{3} \mathrm{H}\right]$-leucine incorporation to protein demonstrated a $50 \%$ increase in protein synthesis in these cells (Figure $7 \mathrm{~b}$ ). Taken together, the results shown in Figures 6 and 7 demonstrate that overexpression of Akt 1 is sufficient to induce polyploidization and hypertrophy in VSMCs.

Akt1 function is required for angiotensin II-induced VSMC polyploidization. Multiple growth factors have been shown to induce Akt 1 activity in VSMCs $(26,48-50$, 68-71). We investigated the ability of angiotensin II (26, $48-50)$, PDGF BB $(50,69)$, and TGF- $\beta(50)$, to modulate the onset of polyploidization in VSMCs. As shown in Figure 8a, angiotensin II, but not PDGF BB or TGF$\beta$, promoted VSMC polyploidization. Furthermore, addition of PDGF BB or TGF- $\beta$ decreased the level of angiotensin II-induced VSMC polyploidization (Figure 8a). To determine whether or not angiotensin II-induced polyploidization was mediated by Akt1, VSMCs were transduced with control or Akt1 AA mutant adenoviruses before stimulation. Expression of Akt1 AA blocked the polyploidization of VSMCs induced by angiotensin II (Figure 8b). Thus, these results demonstrated that Akt 1 function is required for angiotensin II-induced VSMC polyploidization.

\section{Figure 7}

Akt1 promotes VSMC hypertrophy. (a) Flow cytometry of FSC fluorescence (cell size) versus side-scatter cell fluorescence (SSC; cell density) of control, wild-type, and mutant Akt1-expressing VSMCs incubated in 1\% FBS media for 72 hours. Representative of two duplicate experiments. (b) $\left[\mathrm{H}^{3}\right]$ leucine incorporation in control, wild-type, and mutant Akt1-expressing VSMC incubated in 1\% FBS media for 72 hours. Data are expressed in arbitrary units relative to control ( $\beta$ Gal) incorporation. Represents three experiments. Other experimental details as indicated in Methods.

$\mathbf{a}$

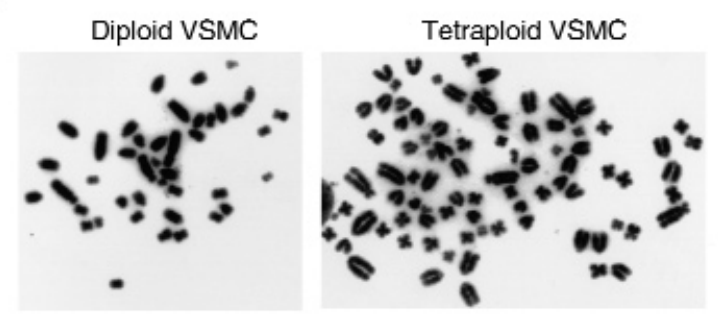

b

PDLs in colcemid

C VSMC at passage 5 $\begin{array}{cccccc}\text { VSMC } & \text { VSMC } & \text { VSMC } & \text { VSMC } & \text { VSMC } & \text { VSMC } \\ \beta \text { Gal } & \text { Akt1 wt } & \text { Akt1 AA } & \text { (parental) } & \beta \text { Gal } & \text { Akt1 wt } \\ \text { 38/39 } & & & 18 / 18 & 16 / 16 & \end{array}$

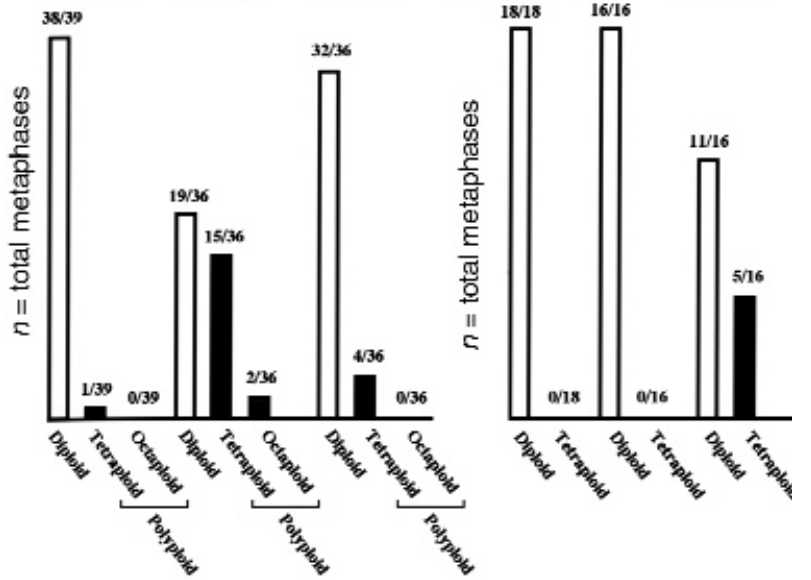

\section{Discussion}

Most plants and animals generate tissue-specific subpopulations of polyploid cells that are larger than their diploid counterparts (72). However, little is known about the molecular events that promote tissue-specific hypertrophy and polyploidization. Here we provide evidence for a role of Akt1 in VSMC hypertrophy and polyploidization, phenomena that occur at capacitance arteries during hypertension $(6-10,17)$. High levels of Akt 1 protein and activity were observed in aortas of hypertensive SHR, Goldblatt-WKY, and Zucker fa/fa rats, which also displayed polyploidization. The increase in basal Akt 1 activity, four to fivefold higher in SHR related to age-matched WKY controls, correlates well with the elevation in Akt1 protein expression. These data provide correlative evidence that Akt 1 is involved in VSMC polyploidization in several experimental models of hypertension. Consistent with these results, recent data from Jiang and coworkers demonstrate that the PI 3-kinase/Akt pathway is reduced in

a

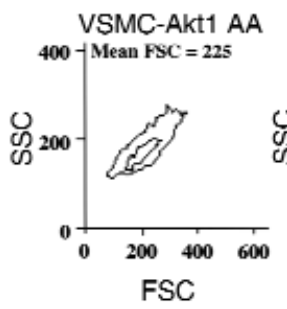

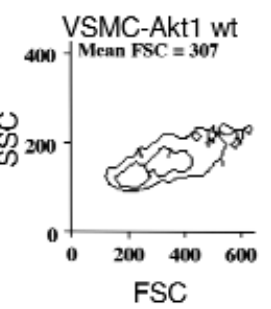

b

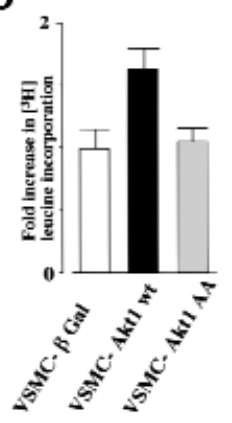




\section{Figure 8}

Akt1 function is required for angiotensin II-induced VSMC polyploidization. (a) Effect of PDGF BB, angiotensin II, and TGF- $\beta$ on VSMC ploidy. WKY VSMCs were incubated for 1 week in $1 \%$ FBS media with $100 \mathrm{ng} / \mathrm{ml}$ of colcemid and no additions (Control), 30 $\mathrm{ng} / \mathrm{ml}$ PDGF BB, $0.1 \mu \mathrm{M}$ angiotensin II (Ang), or $5 \mathrm{ng} / \mathrm{ml} \mathrm{TGF-} \beta$. After incubation, cells were harvested and processed for flow cytometry of DNA content as in Figure 4. Figure shows the percentage of VSMC with greater than $4 \mathrm{~N}$ DNA content. Data represent three independent experiments. (b) Effect of Akt1 AA transduction on angiotensin II-induced VSMC polyploidization. WKY VSMCs were infected with 100 moi's of $\beta$ Gal or Akt 1 AA adenovirus and incubated for 1 week in $1 \%$ FBS media with $100 \mathrm{ng} / \mathrm{ml}$ of colcemid and no additions (Control) or $0.1 \mu \mathrm{M}$ angiotensin II (Ang). After incubation, cells were harvested and processed for flow cytometry of DNA content as in Figure 4. Figure shows the percentage of VSMCs with greater than $4 \mathrm{~N}$ DNA content. Data represent three independent experiments.

\section{a}

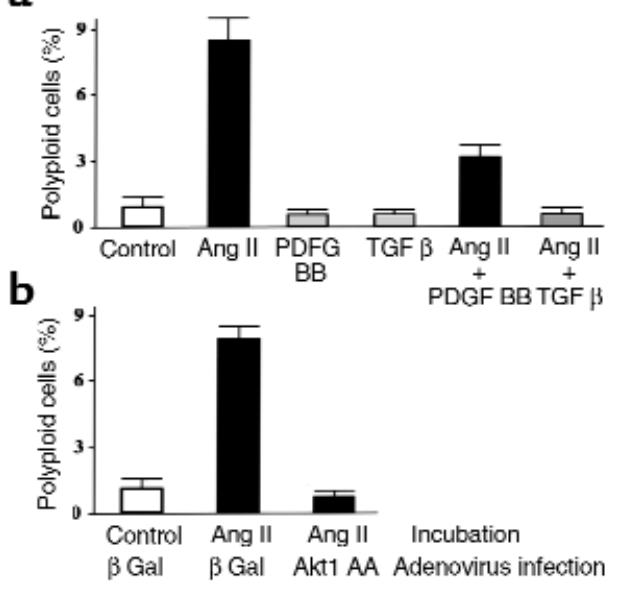

microvessels of Zucker $f a / f a$ rats, whereas a moderate increase in activity was observed in the aorta (73).

To determine the functional significance of the elevated Akt 1 levels in vascular smooth muscle, this protein was overexpressed in VSMCs isolated from the aortas of normotensive rats. Overexpression of wild-type Akt in VSMCs increased Akt1 activity approximately tenfold, within the range of induction observed in smooth muscle cells incubated in the presence of $\mathrm{H}_{2} \mathrm{O}_{2}$ or angiotensin II (26). Importantly, overexpression of wild-type, but not a catalytic inactive, Akt 1 abrogated the activity of the mitotic spindle cell-cycle checkpoint in VSMCs, with corresponding perturbations in the cyclin B expression and DNA endoreduplication. Furthermore, enhanced expression of Akt1 was sufficient to induce polyploidization and hypertrophy in VSMCs. The fact that Akt1 promotes the progression of mitosis ( $M$ phase) parallels other growth-related properties of this protein. Akt1 has been shown to activate NF- $\mathrm{KB}$ activity (46) and c-fos (74), positive regulators of the progression through $\mathrm{G} 1$ cell-cycle phase $(75,76)$. Akt1 also activates E2F, a regulator of the $\mathrm{G} 1 / \mathrm{S}$ transition (44). Collectively, these data demonstrate that Akt1 promotes cell growth by acting at multiple stages of the cell cycle. Akt1 appears to predispose VSMCs to polyploidization because no cell-cycle differences in Akt1 protein levels in VSMCs were found, nor were differences found in Akt levels between tetraploid versus diploid VSMCs (not shown). These data resemble our previous observations in patients with Li-Fraumeni syndrome who carry p53 mutations (57) and strongly suggest that Akt1 does not affect directly the chromosomal segregation machinery, but the pathways that regulate VSMC ploidy content.

Our results indicate that overexpression of Akt 1 in VSMCs overrides the activity of the mitotic spindle checkpoint, facilitating unscheduled degradation of cyclin B, cell-cycle reentry (endoreduplication), and polyploidization. At least two molecular mechanisms can account for these effects of Akt1. First, Akt may directly modulate the expression of cell-cycle regulato- ry proteins. The metabolism of the cyclin $\mathrm{B}-\mathrm{Cdc} 2 \mathrm{com}-$ plex is known to be regulated by its interaction with Cks(s) [in Homo sapiens, CKsHs(s)] $(77,78)$ and by spindle sensor proteins, such as MAD2 (79-81). Therefore, further investigation on the effects of Akt1 on these and other mitotic regulatory factors (82) may reveal the mechanism of cyclin B modulation by Akt1. In addition, polyploid VSMCs may be eliminated by the activity of the postmitotic checkpoint, an apoptotic pathway that target cells that escape the control of the mitotic spindle checkpoint $(83,84)$. Therefore, the antiapoptotic properties of Akt may be necessary to maintain the viability of polyploid VSMCs. In support of this hypothesis, Akt 1 is a regulator of the bcl-2 family protein, $\mathrm{BAD}(37)$, and $\mathrm{Bcl} 2$ family members are known to promote polyploidization in mesenchymal cells (85).

As shown here, angiotensin II, but not PDGF BB or TGF- $\beta$, promoted Akt-dependent VSMC polyploidization. The fact that PDGF BB and TGF- $\beta$, activators of Akt signaling, fail to induce VSMC polyploidization may be related to the ability of these factors to activate additional signal-transduction pathways. For example, PDGF BB activates ERK and P38MAPK activities, which may oppose Akt signaling in smooth muscle (69). Importantly, Mek and p42 MAPK have been shown to trigger G2/M arrest in some systems (86). Likewise, TGF- $\beta$ inhibits WKY VSMC polyploidization $(87,88)$, and this may be mediated by downregulation of Cks1 (89). Therefore, we propose that Akt signaling is both essential and sufficient for VSMC hypertrophy and polyploidization, but this activity can be overridden by factors that promote MAPK signaling and/or that modulate the expression of other cell-cycle regulatory proteins. Consistent with this hypothesis, we found that PDGF BB and TGF- $\beta$ decrease angiotensin II-induced VSMC polyploidization.

In conclusion, we demonstrate that Akt 1 protein levels and kinase activity are elevated in VSMCs that are predisposed to, or undergoing, hypertrophy in several animal models of hypertension. Although it is shown here that Akt1 is sufficient for the induction of VSMC 
hypertrophy and polyploidization, an unresolved issue is the nature of the causal relationship between polyploidization and hypertrophy. On one hand, hypertrophy, i.e., cell enlargement, may induce polyploidization. Alternatively, polyploidization may be an essential feature of the hypertrophic process. Evidence for the latter hypothesis comes from the recent finding of DNA ploidy-driven mechanisms of control of gene expression (90). In this study, an increase in cell size was explained by the longer G1 cell-cycle phase of polyploid yeast cells, which express low levels of G1 cyclins. Consistent with this hypothesis is the observation that tetraploid VSMCs exhibit longer population-doubling rates than their diploid counterparts $(91,92)$. Therefore, further investigation on the functions of Akt1 should provide additional information regarding the interrelationship between VSMC hypertrophy and polyploidization, and the molecular mechanisms that control these processes.

\section{Acknowledgments}

We thank K. Guo, E.R. Chan, P.N. Tsichlis, and A. Scarpa for reagents and suggestions. This work was supported in part by grants from Ohio Cancer Research Associates, the American Heart Association, and NIH to A. Gualberto, T. Hassold, and K. Walsh.

1. Lehmann, E.D., Watts, G.F., Fatemi-Langroudi, B., and Gosling, R.G 1992. Aortic compliance in young patients with heterozygous familial hypercholesterolaemia. Clin. Sci. (Colch.) 83:717-721.

2. Lehmann, E.D., Gosling, R.G., and Sonksen, P.H. 1992. Arterial wall compliance in diabetes. Diabet. Med. 9:114-119.

3. Toto-Moukouo, J.J., Achimastos, A., Asmar, R.G., Hugues, C.J., and Safar, M.E. 1986. Pulse wave velocity in patients with obesity and hypertension. Am. Heart J. 112:136-140.

4. Owens, G.K., Rabinovitch, P.S., and Schwartz, S.M. 1981. Smooth muscle cell hypertrophy versus hyperplasia in hypertension. Proc. Natl. Acad. Sci. USA. 78:7759-7763.

5. Olivetti, G., Anversa, P., Melissari, M., and Loud, A.V. 1980. Morphometry of medial hypertrophy in the rat thoracic aorta. Lab. Invest. 42:559-565.

6. Owens, G.K., and Schwartz, S.M. 1982. Alterations in vascular smooth muscle mass in the spontaneously hypertensive rat. Role of cellular hypertrophy, hyperploidy, and hyperplasia. Circ. Res. 51:280-289.

7. Barrett, T.B., Sampson, P., Owens, G.K., Schwartz, S.M., and Benditt, E.P. 1983. Polyploid nuclei in human artery wall smooth muscle cells. Proc. Natl. Acad. Sci. USA. 80:882-885.

8. Lee, R.M., Conyers, R.B., and Kwan, C.Y. 1992. Incidence of multinucleated and polyploid aortic smooth muscle cells cultured from different age groups of spontaneously hypertensive rats. Can. J. Physiol. Pharmacol. 70:1496-1501.

9. Conyers, R.B., Kwan, C.Y., and Lee, R.M. 1995. Alterations in betaadrenoceptors and polyploidy in cultured aortic smooth muscle cells from different age groups of spontaneously hypertensive rats and Wistar-Kyoto rats. J. Hypertens. 13:507-515.

10. Dominiczak, A.F., et al. 1996. Vascular smooth muscle polyploidy and cardiac hypertrophy in genetic hypertension. Hypertension. 27:752-759.

11. van Neck, J.W., et al. 1992. Effect of ploidy on transcription levels in cultured rat aortic smooth muscle cells. FEBS Lett. 297:189-195.

12. Yamori, Y., Mano, M., Nara, Y., and Horie, R. 1987. Catecholamineinduced polyploidization in vascular smooth muscle cells. Circulation. 75:192-I95

13. Black, M.J., Adams, M.A., Bobik, A., Campbell, J.H., and Campbell, G.R. 1989. Effect of enalapril on aortic smooth muscle cell polyploidy in the spontaneously hypertensive rat. J. Hypertens. 7:997-1003.

14. Black, M.J., Bertram, J.F., Campbell, J.H., and Campbell, G.R. 1995. Angiotensin II induces cardiovascular hypertrophy in perindopriltreated rats. J. Hypertens. 13:683-692.

15. Devlin, A.M., et al. 1995. Vascular smooth muscle polyploidy in genetic hypertension: the role of angiotensin II. J. Hum. Hypertens. 9:497-500.
16. Devlin, A.M., et al. 1995. The effects of perindopril on vascular smooth muscle polyploidy in stroke-prone spontaneously hypertensive rats. J. Hypertens. 13:211-218.

17. Owens, G.K., and Schwartz, S.M. 1983. Vascular smooth muscle cell hypertrophy and hyperploidy in the Goldblatt hypertensive rat. Circ. Res. 53:491-501.

18. Murray, A.W., and Mitchison, T.J. 1994. Mitosis. Kinetochores pass the IQ test. Curr. Biol. 4:38-41.

19. Nicklas, R.B. 1997. How cells get the right chromosomes. Science. 275:632-637.

20. Elledge, S.J. 1996. Cell cycle checkpoints: preventing an identity crisis. Science. 274:1664-1672.

21. Jaspersen, S.L., Charles, J.F., Kulberg, R.L., Tinker, and Morgan, D.O 1998. A late mitotic regulatory network controlling cyclin destruction in Saccharomyces cerevisiae. Mol. Biol. Cell. 9:2803-2817.

22. Hemmings, B.A. 1997. Akt signaling: linking membrane events to life and death decisions. Science. 275:628-630.

23. Hemmings, B.A. 1997. PtdIns(3,4,5)P3 gets its message across. Science. 277:534.

24. Franke, T.F., et al. 1995. The protein kinase encoded by the Akt protooncogene is a target of the PDGF-activated phosphatidylinositol 3kinase. Cell. 81:727-736.

25. Fujio, Y., and Walsh, K. 1999. Akt mediates cytoprotection of endothelial cells by vascular endothelial growth factor in an anchoragedependent manner. J. Biol. Chem. 274:16349-16354.

26. Ushio-Fukai, M., et al. 1999. Reactive oxygen species mediate the activation of Akt/protein kinase B by angiotensin II in vascular smooth muscle cells. J. Biol. Chem. 274:22699-22704.

27. Tanti, J.F., et al. 1997. Potential role of protein kinase B in glucose transporter 4 translocation in adipocytes. Endocrinology. 138:2005-2010.

28. Kohn, A.D., Summers, S.A., Birnbaum, M.J., and Roth, R.A. 1996. Expression of a constitutively active Akt Ser/Thr kinase in 3T3-L1 adipocytes stimulates glucose uptake and glucose transporter 4 translocation. J. Biol. Chem. 271:31372-31378.

29. Cross, D.A., Alessi, D.R., Cohen, P., Andjelkovich, M., and Hemmings, B.A. 1995. Inhibition of glycogen synthase kinase-3 by insulin mediated by protein kinase B. Nature. 378:785-789.

30. Franke, T.F., Kaplan, D.R., Cantley, L.C., and Toker, A. 1997. Direct regulation of the Akt proto-oncogene product by phosphatidylinositol-3,4-bisphosphate. Science. 275:665-668.

31. Dudek, H., et al. 1997. Regulation of neuronal survival by the serinethreonine protein kinase Akt. Science. 275:661-665.

32. Kauffmann-Zeh, A., et al. 1997. Suppression of c-Myc-induced apoptosis by Ras signalling through PI(3)K and PKB. Nature. 385:544-548.

33. Kennedy, S.G., et al. 1997. The PI 3-kinase/Akt signaling pathway delivers an anti-apoptotic signal. Genes Dev. 11:701-713.

34. Kulik, G., Klippel, A., and Weber, M.J. 1997. Antiapoptotic signalling by the insulin-like growth factor I receptor, phosphatidylinositol 3kinase, and Akt. Mol. Cell. Biol. 17:1595-1606.

35. Fujio, Y., et al. 1999. Cell cycle withdrawal promotes myogenic induction of akt, a positive modulator of myocyte survival. Mol. Cell. Biol. 19:5073-5082.

36. del Peso, L., Gonzalez-Garcia, M., Page, C., Herrera, R., and Nunez, G. 1997. Interleukin-3-induced phosphorylation of BAD through the protein kinase Akt. Science. 278:687-689.

37. Datta, S.R., et al. 1997. Akt phosphorylation of BAD couples survival signals to the cell-intrinsic death machinery. Cell. 91:231-241.

38. Yano, S., Tokumitsu, H., and Soderling, T.R. 1998. Calcium promotes cell survival through CaM-K kinase activation of the protein-kinaseB pathway. Nature. 396:584-587

39. Cardone, M.H., et al. 1998. Regulation of cell death protease caspase9 by phosphorylation. Science. 282:1318-1321.

40. Brunet, A., et al. 1999. Akt promotes cell survival by phosphorylating and inhibiting a Forkhead transcription factor. Cell. 96:857-868.

41. Kops, G.J., et al. 1999. Direct control of the Forkhead transcription factor AFX by protein kinase B. Nature. 398:630-634

42. Nakae, J., Park, B.C., and Accili, D. 1999. Insulin stimulates phosphorylation of the forkhead transcription factor FKHR on serine 253 through a wortmannin-sensitive pathway. J. Biol. Chem. 274:15982-15985.

43. Tang, E.D., Nunez, G., Barr, F.G., and Guan, K.L. 1999. Negative regulation of the forkhead transcription factor FKHR by Akt. J. Biol. Chem. 274:16741-16746.

44. Brennan, P., et al. 1997. Phosphatidylinositol 3-kinase couples the interleukin-2 receptor to the cell cycle regulator E2F. Immunity. 7:679-689.

45. Chang, H.W., et al. 1997. Transformation of chicken cells by the gene encoding the catalytic subunit of PI 3-kinase. Science. 276:1848-1850.

46. Kane, L.P., Shapiro, V.S., Stokoe, D., and Weiss, A. 1999. Induction of NF-kappaB by the Akt/PKB kinase. Curr. Biol. 9:601-604.

47. Skorski, T., et al. 1997. Transformation of hematopoietic cells by 
$\mathrm{BCR} / \mathrm{ABL}$ requires activation of a PI-3k/Akt-dependent pathway. EMBO J. 16:6151-6161.

48. Eguchi, S., et al. 1999. Intracellular signaling of angiotensin II-induced p70 S6 kinase phosphorylation at Ser(411) in vascular smooth muscle cells. Possible requirement of epidermal growth factor receptor, Ras, extracellular signal-regulated kinase, and Akt. J. Biol. Chem. 274:36843-36851.

49. Takahashi, T., et al. 1999. Activation of Akt/protein kinase B after stimulation with angiotensin II in vascular smooth muscle cells. Am. J. Physiol. 276:H1927-H1934.

50. Higaki, M., and Shimokado, K. 1999. Phosphatidylinositol 3-kinase is required for growth factor-induced amino acid uptake by vascular smooth muscle cells. Arterioscler. Thromb. Vasc. Biol. 19:2127-2132.

51. Shabaik, A.S., Pow-Sang, J.M., Lockhart, J., and Nicosia, S.V. 1993. Role of DNA image cytometry in the follow-up of patients with urinary tract transitional cell carcinoma. Anal. Quant. Cytol. Histol. 15:115-123.

52. Owens, G.K., Schwartz, S.M., and McCanna, M. 1988. Evaluation of medial hypertrophy in resistance vessels of spontaneously hypertensive rats. Hypertension. 11:198-207.

53. Owens, G.K., Loeb, A., Gordon, D., and Thompson, M.M. 1986. Expression of smooth muscle-specific alpha-isoactin in cultured vascular smooth muscle cells: relationship between growth and cytodifferentiation. J. Cell. Biol. 102:343-352.

54. Miano, J.M., Cserjesi, P., Ligon, K.L., Periasamy, M., and Olson, E.N. 1994. Smooth muscle myosin heavy chain exclusively marks the smooth muscle lineage during mouse embryogenesis. Circ. Res. 75:803-812.

55. Alessi, D.R., et al. 1996. Mechanism of activation of protein kinase B by insulin and IGF-1. EMBO J. 15:6541-6551.

56. Rajvanshi, P., et al. 1998. Fractionation of rat hepatocyte subpopulations with varying metabolic potential, proliferative capacity, and retroviral gene transfer efficiency. Exp. Cell Res. 244:405-419.

57. Gualberto, A., Aldape, K., Kozakiewicz, K., and Tlsty, T.D. 1998. An oncogenic form of $\mathrm{p} 53$ confers a dominant, gain-of-function phenotype that disrupts spindle checkpoint control. Proc. Natl. Acad. Sci. USA. 95:5166-5171.

58. Hixon, M.L., Flores, A.I., Wagner, M.W., and Gualberto, A. 1998. Ectopic expression of $\mathrm{cdc} 2 / \mathrm{cdc} 28$ kinase subunit homo sapiens 1 uncouples cyclin B metabolism from the mitotic spindle cell cycle checkpoint. Mol. Cell. Biol. 18:6224-6237.

59. Yamori, Y. 1994. Development of the spontaneously hypertensive rat (SHR), the stroke-prone SHR (SHRSP) and their various substrain models for hypertension-related cardiovascular diseases. In Experimental and genetic models of hypertension. Volume 16. D. Ganten and W. de Jong, editors. Elsevier. Amsterdam, The Netherlands. 346-364.

60. Kurtz, T.W., Morris, R.C., and Pershadsingh, H.A. 1989. The Zucker fatty rat as a genetic model of obesity and hypertension. Hypertension. 13:896-901.

61. Lombardi, D.M., Owens, G.K., and Schwartz, S.M. 1989. Ploidy in mesenteric vessels of aged spontaneously hypertensive and WistarKyoto rats. Hypertension. 13:475-479.

62. Su, E.J., Lombardi, D.M., Siegal, J., and Schwartz, S.M. 1998 Angiotensin II induces vascular smooth muscle cell replication independent of blood pressure. Hypertension. 31:1331-1337.

63. Black, M.J., Campbell, J.H., and Campbell, G.R. 1988. Does smooth muscle cell polyploidy occur in resistance vessels of spontaneously hypertensive rats? Blood Vessels. 25:89-100.

64. Marte, B.M., and Downward, J. 1997. PKB/Akt: connecting phosphoinositide 3-kinase to cell survival and beyond. Trends Biochem. Sci. 22:355-358.

65. Koepp, D.M., Harper, J.W., and Elledge, S.J. 1999. How the cyclin became a cyclin: regulated proteolysis in the cell cycle. Cell. 97:431-434.

66. Gille, H., and Downward, J. 1999. Multiple ras effector pathways contribute to G(1) cell cycle progression. J. Biol. Chem. 274:22033-22040.

67. Rosen, E.M., et al. 1986. Strain and site dependence of polyploidization of cultured rat smooth muscle. J. Cell. Physiol. 128:337-344.

68. Duan, C., Liimatta, M.B., and Bottum, O.L. 1999. Insulin-like growth factor (IGF)-I regulates IGF-binding protein-5 gene expression through the phosphatidylinositol 3-kinase, protein kinase B/Akt, and p70 S6 kinase signaling pathway. J. Biol. Chem. 274:37147-37153.

69. Hayashi, K., et al. 1999. Changes in the balance of phosphoinositide 3 -kinase/protein kinase $\mathrm{B}(\mathrm{Akt})$ and the mitogen-activated protein kinases (ERK/p38MAPK) determine a phenotype of visceral and vascular smooth muscle cells. J. Cell Biol. 145:727-740.

70. Imai, Y., and Clemmons, D.R. 1999. Roles of phosphatidylinositol 3kinase and mitogen-activated protein kinase pathways in stimulation of vascular smooth muscle cell migration and deoxyribonucleic acid synthesis by insulin-like growth factor-I. Endocrinology. 140:4228-4235

71.Jiang, Z.Y., et al. 1999. Endothelin-1 modulates insulin signaling through phosphatidylinositol 3-kinase pathway in vascular smooth muscle cells. Diabetes. 48:1120-1130.

72. Hieter, P., and Griffiths, T. 1999. Polyploidy: more is more or less. Science. 285:210-211.

73. Jiang, Z.Y., et al. 1999. Characterization of selective resistance to insulin signaling in the vasculature of obese Zucker (fa/fa) rats. J. Clin. Invest. 104:447-457.

74. Wang, Y., et al. 1998. Activation of the $\mathrm{c}$-fos serum response element by phosphatidyl inositol 3-kinase and rho pathways in HeLa cells. Cell Growth Differ. 9:513-522.

75. Cosenza, S.C., Owen, T.A., Soprano, D.R., and Soprano, K.J. 1988. Evidence that the time of entry into $S$ is determined by events occurring in early G1. J. Biol. Chem. 263:12751-12758.

76. Baldwin, A.S., Jr., Azizkhan, J.C., Jensen, D.E., Beg, A.A., and Coodly, L.R. 1991. Induction of NF-kappa B DNA-binding activity during the G0-toG1 transition in mouse fibroblasts. Mol. Cell. Biol. 11:4943-4951.

77. Basi, G., and Draetta, G. 1995. The cdc2 kinase: structure, activation, and its role at mitosis in vertebrate cells. In Cell cycle control. Volume 10. C. Hutchison and D.M. Glover, editors. Oxford University Press. Oxford, United Kingdom. 106-134.

78. Richardson, H.E., Stueland, C.S., Thomas, J., Russell, P., and Reed, S.I. 1990. Human cDNAs encoding homologs of the small p34Cdc28/Cdc2-associated protein of Saccharomyces cerevisiae and Schizosaccharomyces pombe. Genes Dev. 4:1332-1344.

79. Chen, R.H., Waters, J.C., Salmon, E.D., and Murray, A.W. 1996. Association of spindle assembly checkpoint component XMAD2 with unattached kinetochores. Science. 274:242-246.

80. Li, Y., and Benezra, R. 1996. Identification of a human mitotic checkpoint gene: hsMAD2. Science. 274:246-248.

81. Pangilinan, F., and Spencer, F. 1996. Abnormal kinetochore structure activates the spindle assembly checkpoint in budding yeast. Mol. Biol. Cell. 7:1195-1208.

82. Hixon, M.L., and Gualberto, A. 2000. The control of mitosis. Front. Biosci. 5:D50-D57.

83. Lanni, J.S., and Jacks, T. 1998. Characterization of the p53-dependent postmitotic checkpoint following spindle disruption. Mol. Cell. Biol. 18:1055-1064.

84. Sherwood, S.W., Sheridan, J.P., and Schimke, R.T. 1994. Induction of apoptosis by the anti-tubulin drug colcemid: relationship of mitotic checkpoint control to the induction of apoptosis in HeLa S3 cells. Exp. Cell Res. 215:373-379.

85. Minn, A.J., Boise, L.H., and Thompson, C.B. 1996. Expression of Bcl$\mathrm{xL}$ and loss of $\mathrm{p} 53$ can cooperate to overcome a cell cycle checkpoint induced by mitotic spindle damage. Genes Dev. 10:2621-2631.

86. Walter, S.A., Guadagno, T.M., and Ferrell, J.E., Jr. 1997. Induction of a G2-phase arrest in Xenopus egg extracts by activation of p42 mitogen-activated protein kinase. Mol. Biol. Cell. 8:2157-2169.

87. Agrotis, A., Saltis, J., Dilley, R., Bray, P., and Bobik, A. 1995. Transforming growth factor-beta 1 and the development of vascular hypertrophy in hypertension. Blood Press. Suppl. 2:43-48.

88. Gibbons, G.H., Pratt, R.E., and Dzau, V.J. 1992. Vascular smooth muscle cell hypertrophy vs. hyperplasia. Autocrine transforming growth factor-beta 1 expression determines growth response to angiotensin II. J. Clin. Invest. 90:456-461.

89. Simon, K.E., Cha, H.H., and Firestone, G.L. 1995. Transforming growth factor beta down-regulation of CKShs 1 transcripts in growthinhibited epithelial cells. Cell Growth Differ. 6:1261-1269.

90. Galitski, T., Saldanha, A.J., Styles, C.A., Lander, E.S., and Fink, G.R. 1999. Ploidy regulation of gene expression. Science. 285:251-254.

91. Rosen, E.M., et al. 1985. Growth kinetics as a function of ploidy in diploid, tetraploid, and octaploid smooth muscle cells derived from the normal rat aorta. J. Cell. Physiol. 125:512-250.

92. Goldberg, I.D., et al. 1984. Isolation and culture of a tetraploid subpopulation of smooth muscle cells from the normal rat aorta. Science. 226:559-561 